Larysa Strashynska, Ph.D. in Economics., Professor, National University of Food Technologies (Kyiv, Ukraine)

Volodymyr Strashynskyi, National Pedagogical Dragomanov University (Kyiv, Ukraine)

\title{
SYSTEMATIZATION OF FACTORS INFLUENCING COMPETITIVENESS OF FOOD PRODUCTS
}

\begin{abstract}
The article examines and generalizes factors that influence the competitiveness of products. From the investigated factors are allocated and structured factors influencing the competitiveness offood products. The most important of them - safety, quality and price. Also considered are factors such as trademark, advertising, competitors behavior, packaging, sales promotion, functionality, etc. It is established that in the aggregate all factors are the system of food products competitiveness at a separate food enterprise, and each individual factor depends on a number of other indicators. Affecting the competitiveness of products, factors change each other. Thus, the manufacturer must take into account the optimal ratio of factors of competitiveness of products.
\end{abstract}

Keywords: competitiveness, food products, factors influencing competitiveness, safety, quality, trade mark, advertising, behavior of competitors, sales promotion, packaging functions

\section{Formulation of the problem}

Provision and formation of competitive food products is an urgent task for domestic food companies. For the manufacturer it is important not only to enter the market with its product, but also to keep it, while gaining profit and increasing sales. Enterprises in the food industry are compelled to compete not only with foreign producers with a wealth of experience and financial resources, but also with each other. To consolidate its position on the market among many competitors its product must be competitive, that is, possess a set of consumer and cost characteristics of the product, which determine its success in the market. Competition compels the manufacturer to engage in a quality system, service improvement, customer needs survey.

In spite of the great attention to the problem of competitiveness, the unanimous opinion on its essence, the methodology of evaluation, the factors that determine it, at present does not exist. Thus, the study of the factors affecting the competitiveness of food products allows us to understand how they promote or hinder the growth of its competitiveness. This is due to the fact that the production activity of the enterprise in modern conditions depends on how successfully the problems connected with the competitiveness of the manufactured products are solved. 


\section{Analysis of research and publications}

The concepts and problems associated with the definition of competitiveness in general, as well as the competitiveness of products, were reflected in the works of a number of prominent economists, in particular I. Kolomeytsya, V. Koreneva, F. Kotler, V. Osipov, M. Porter, S. Savchuk, N. Tarnavska, R. Fatkhutdinova and many others. However, in most sources, the concept of "competitiveness" is considered abstractly and does not cover all possible parameters that can be used for its assessment, and factors affecting the competitiveness of products.

The purpose of this study is to systematize and analyze the diversity of factors that determine the competitiveness of food products.

\section{Presenting main material}

On the basis of the study and analysis of literature [1-5], taking into account the existing classifications studied, the author systematized the factors that determine the competitiveness of products (Fig. 1).

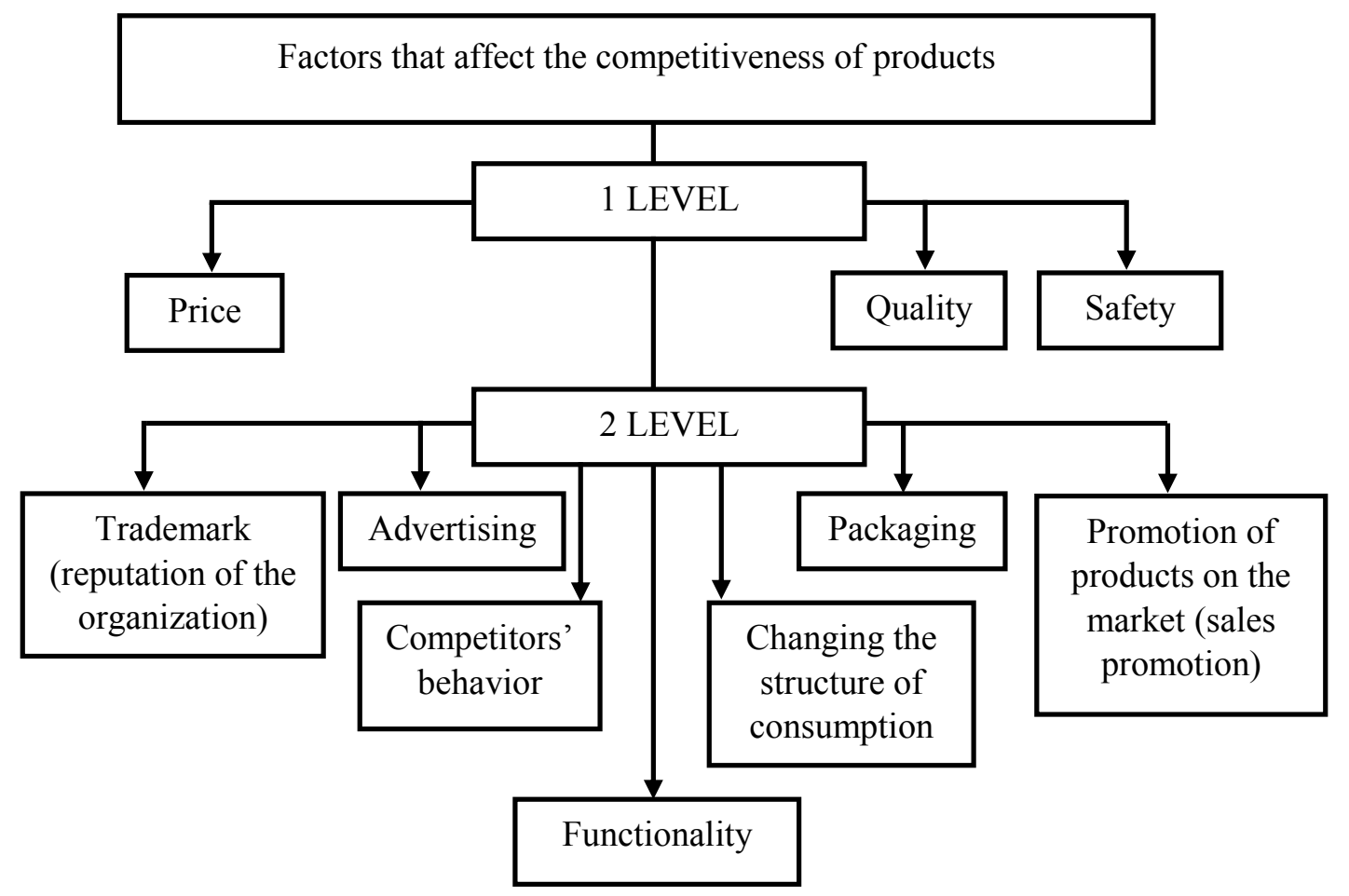

Fig. 1. Systematization of factors influencing the competitiveness of products, taking into account different classifications

The proposed systematization shows that there are many classifications of product competitiveness, but in this study it is worth approaching the problem of determining the factors affecting the competitiveness of food products directly, based on the fact that this category is implemented when the product is recognized by the consumer (in the process of sale). 
Among the variety of factors affecting the competitiveness of products, for the enterprises of the food industry, the author identifies the main factors of the competitiveness of products in this industry. They are conditionally divided into two levels (Fig. 2).

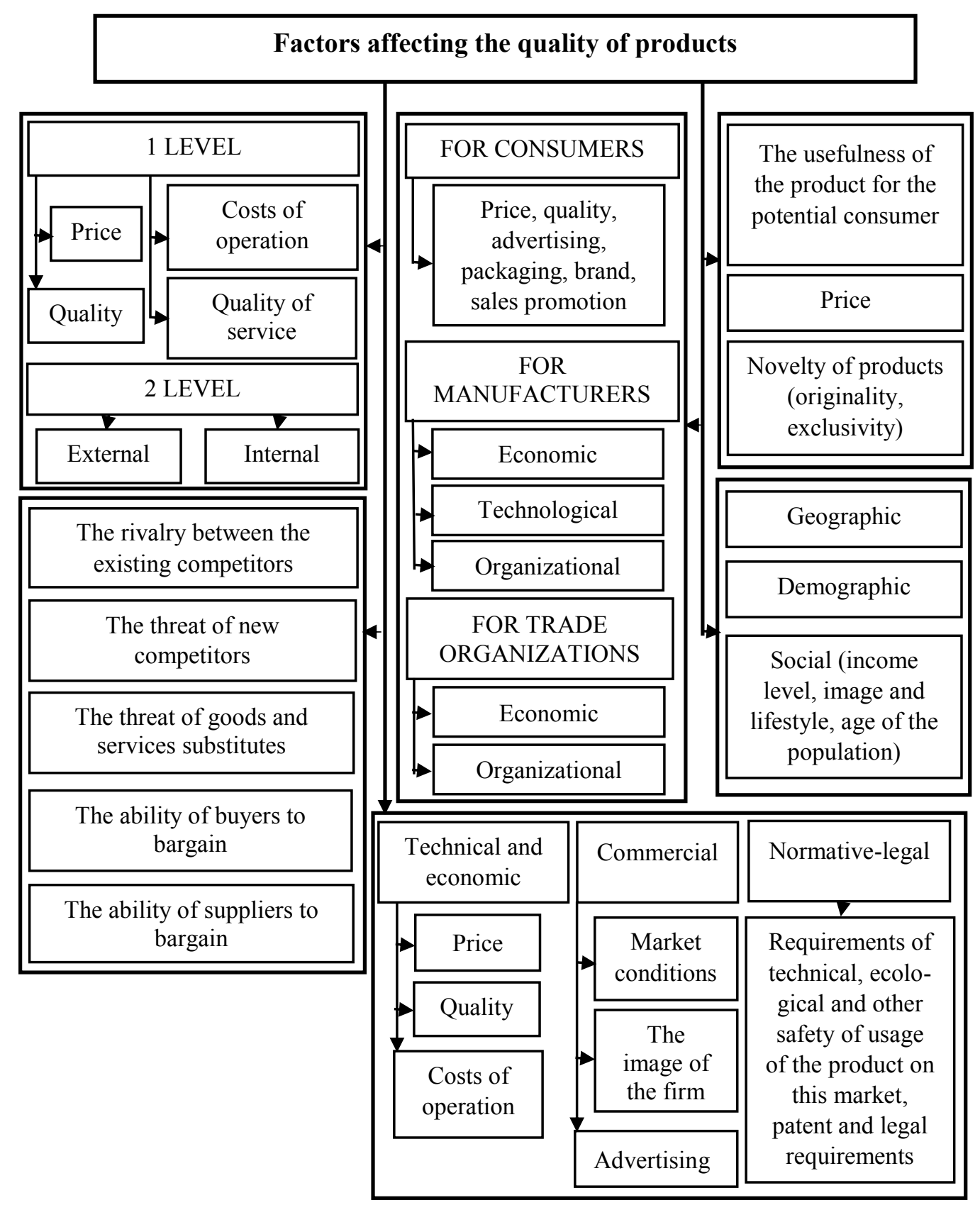

Fig. 2. The main factors influencing the competitiveness of food products

To the first level it is necessary to include the three most important factors - the price, quality and safety of products. This is due to the fact that the consumer is most interested in the qualitative characteristics of products, the confidence in its safety and the cost of its acquisition. It should be noted that quality and safety are closely linked, because the health of the consumer is directly related to the food he consumes. Manufacturers should meet the growing demand of consumers 
for safe and high-quality food. In the conditions of dynamic development of market relations and competition food industry enterprises should ensure quality, stability and safety of products, which will help increase the competitiveness of both enterprises and finished products.

The quality of food products is understood as a set of characteristics of food products that can meet the human's need for food under normal conditions of its usage, compliance with regulatory documents, the absence of defects, etc. Organoleptic quality indicators are important for food products - appearance, consistency, taste, color and smell. This is due to the fact that after tasting the consumer determines whether to re-purchase this product or not. However, we should not forget about the microbiological and physico-chemical indicators of the quality of food products that affect the safety of the product.

The buyer must be sure of the consumed products' safety, and this is possible only with mandatory certification. Under the safety of food products, the state of the foodstuff is understood, indicating that there is no unacceptable risk associated with harmful effects on human life and health [].

In the process of production and sale of food products in the trading network, it is necessary to identify all possible factors and risks, carry out their detailed analysis using the basic principles of the quality management system, evaluate their significance for each process, and introduce a system of preventive measures. All this will guarantee the quality and safety of products, and ultimately - increase the competitiveness of the finished product.

In the conditions of price competition, the price of the product comes to the fore as the market conquest is carried out by lower prices for products compared with competitors. Price is a decisive factor in determining the consumer's intent to purchase the product. If even the highest quality products are set to the highest price that is not available to the consumer, the chances of selling such products are practically reduced to zero.

The current state of the food market is characterized by the fact that numerous manufacturers offer consumers goods with similar names, similar functional properties and close to each other in the price range. In conditions of hard competition it is important to know how to differentiate your product and promote it effectively. For this reason, the factors of the second level play a special role for the consumer at an equivalent price and quality of the competitors' products.

The formation of public opinion is essential to attract a buyer to the choice of a particular product, as competition with the intensification of the involvement of the consumer becomes more difficult, and in order to retain it, a whole art is necessary. Here its role is played by advertising, trade mark (image) and packing of goods. 
In order to make a purchase decision of a food product, the consumer must have some information about it. Advertising (in periodicals, on television, radio, via the Internet, posters, booklets, presentations, tastings, etc.) is used to disseminate such information. Commodity advertising seeks to reach the brand's reputation, and after reaching it to remind consumers of its benefits.

The trademark allows you to distinguish the products of the enterprise from the products of its competitors, is a symbol that confirms the company's high reputation. A good reputation helps to increase the psychological value of products and attract new customers. Only a stable positive opinion of consumers about the quality and dignity of a food product of a particular manufacturer will ensure its high competitiveness. The company's high reputation serves as a guarantee to the consumer of the products' quality being sold and /or the service provided. According to studies, $62 \%$ of consumers believe that a company with a good reputation will not sell products of inadequate quality. The public confidence in the fact that a company with a positive reputation will not sell poor-quality goods will be reflected in the increasing speed and volume of sales. Characteristics of a good reputation (trade mark) are: reliability, support, trust, positive feedback.

An effective way to increase competitiveness is to use packaging to stimulate sales. This is due to the fact that the packaging has certain qualities (Fig. 3).

Thus, product packaging is not only a way of preserving it, but also part of the company's marketing strategy, a factor that affects product safety, its quality, price and, ultimately, its competitiveness. Before choosing, the consumer looks at shelves for a few seconds. In this short time, the packaging should overshadow the others. At the same time, its design is important - the form, color decision, the order of drawing and the sufficiency of information.

An important factor affecting the competitiveness of a food product of a particular manufacturer is the behavior of competitors. It can be aimed at creating new food products or "copying" existing products, but may be based on the desire to preserve the product on the market, for example, by improving its quality, improving packaging, etc. For the success of products on the market, it is necessary, first of all, to identify the main competitors, evaluate their applied tactics of behavior on the market, to monitor its changes. It should be noted that the active position of competitors leads to a decrease in the competitiveness of products, and vice versa. 


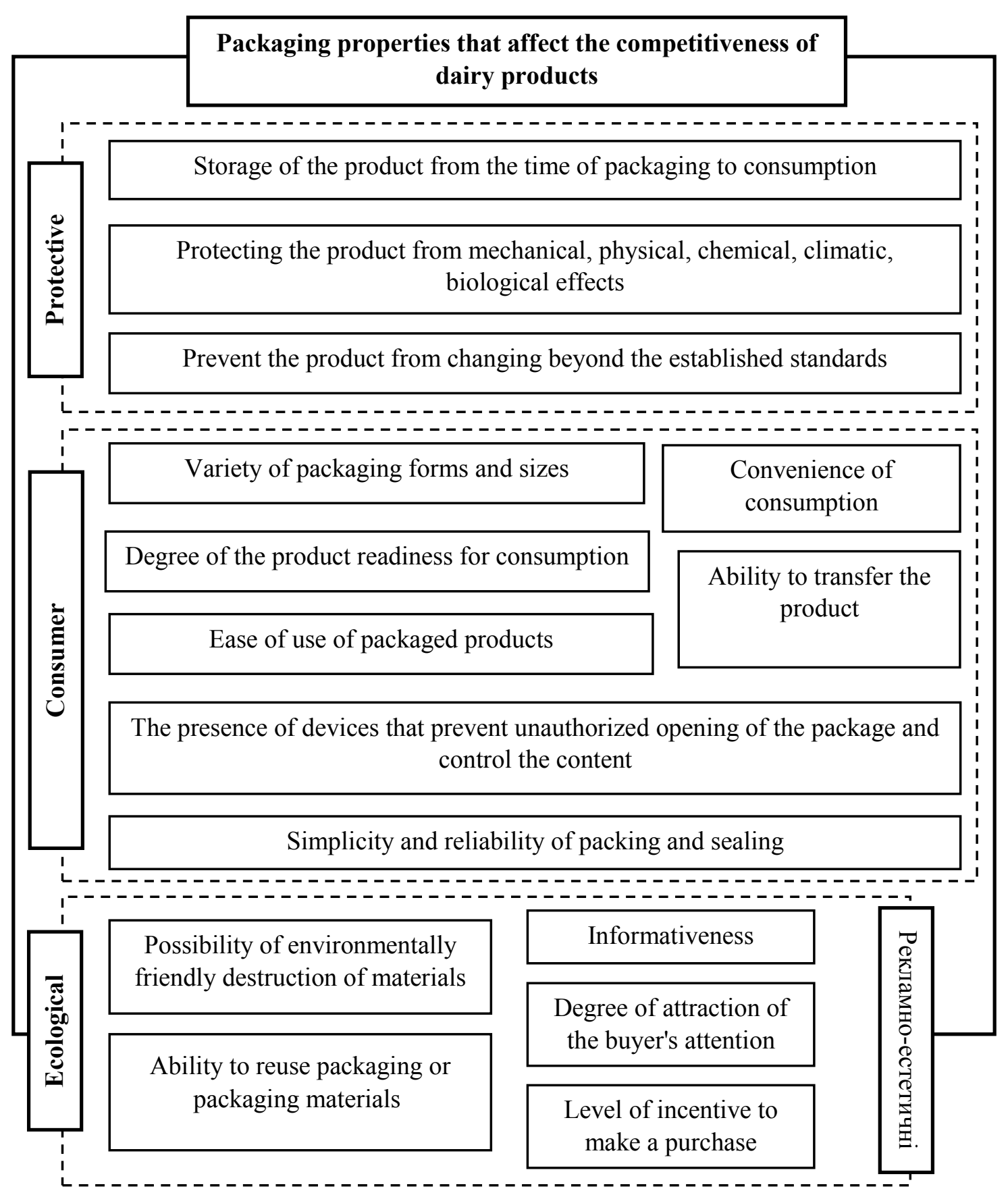

Fig. 3. Packaging properties that affect competitiveness

A sufficiently specific factor of product competitiveness is the change in consumption patterns. This is due to the fact that the needs of the buyer are constantly changing and for their satisfaction, the food business must constantly update the range of products, for example, by improving consumer properties or developing new products. With the increase in the welfare of consumers there are additional opportunities: the consumption of milk is reduced, and the demand for dairy products with additional benefits increases, for example, with improved taste, the addition of juices, vitamins, minerals, useful bacteria, etc. There is an interesting factor in the functionality of the dairy product, as more and more people are trying to lead a healthy lifestyle, and food 
manufacturers began to think about how to make their produce not only tasty and high-quality, but also useful. In this regard, functional foods are becoming increasingly popular, that is, specific foods intended for the systematic use of food rations in all age groups of the population, possessing scientifically substantiated and validated properties that reduce the risk of developing food-related diseases, which prevent the deficit or replenish existing in the human body deficiency of nutrients that save and improve health due to their physiological composition functional food ingredients. In particular, promoting the "functionality" of the product, namely its usefulness to health, for example, to increase immunity, normalize microflora, etc., the manufacturer attracts the attention of a certain group of consumers who want to use drugs in a relatively short time (for example, in two weeks consumption) to improve the state of the organism. In this case, the relationship between such factors that affect the competitiveness of products, as advertising and "functionality" is observed. After all, in order for the potential consumer to buy and continue to buy a useful product, it's worth find out about it at first.

Promotion of products on the market is the final stage of the enterprise to create, produce and bring the goods to the consumer. At this stage, the consumer recognizes if the product is necessary for himself or not and, accordingly, buys this product or not. To implement this stage, it is necessary to create convenient, favorable conditions for the purchase of products, using tools for stimulating sales. For consumers - it's tastings, lotteries, additional goods in the package, gifts, free postal awards, contests, guarantee of return, coupons, sequential series, etc. For wholesale and retail organizations - loans, training, special customer clubs, free samples, bulk buy discounts, urgent discounts, and more. Competition between companies and their products is increasing, and it's increasingly difficult for consumers to distinguish competing brands. Firms-rivals increase incentives, and consumers are focusing better on their products, here helps advertising and packaging products.

\section{Conclusions}

The factors of competitiveness of food products highlighted in the study are closely interrelated. It is clear that the change in one of them will lead to changes in others, and ultimately - will change the level of competitiveness of products. Together, all factors are the system of competitiveness of food products at the company of a specific industry. Each individual factor also depends on a number of other indicators, for example, the quality of products depends on the raw material and functional ingredients, production technology, the state of technological control of production, storage conditions, transportation and implementation, etc. The value of each individual factor varies depending on the market, the nature of the competition, the stage of the life cycle of 
the product, and so on. Affecting the competitiveness of products, factors change each other. It is worth noting the existence of a systemic effect of the factors of competitiveness: for instance, the close implementation of factors, for example, the joint use of advertising, packaging and sales promotion, will result in a much greater effect than the use of these factors separately or depending on each other. For enterprises in the food industry, it is necessary to find the optimal ratio of the factors of product competitiveness, orienting this ratio to the corresponding group of consumers of the target market (for example, functional products - for adherents of healthy eating). Application of the above mentioned factors of competitiveness of food products in their totality will ensure the efficiency of production and competitiveness of products and enterprises in general.

\section{Bibliography}

1. Lyfits I.M. Competitiveness of goods and services / I.M. Lifits - M .: Higher education, 2007. - 390 p.

2. Mazilkina E.I. Competitiveness Management / E.I. Mazilkina, G.G. Panichkina - M .: Omega-L, 2009. - 328 p.

3. Porter M. Competition / M.Porter. - M .: Williams Publishing House, 2010. - 495 p.

4. Rafel M. How to win the client / M. Raphel, N. Rafel. - :Publishing House "Peter", 2006. - 352 p.

5. Fatkhutdinova R. A. Management of Competitiveness of the Organization / R.A. Fatkhutdinova - M .: Eksmo, 2005. - 544 pp. 